\title{
A Review on Metal Nanostructures: Preparation Methods and Their Potential Applications
}

\author{
Umair Yaqub Qazi*, Rahat Javaid \\ Fukushima Renewable Energy Institute, National Institute of Advanced Industrial Science and Technology, AIST, \\ Koriyama, Japan \\ Email: "umair_qazi@yahoo.com
}

Received 4 November 2015; accepted 3 February 2016; published 6 February 2016

Copyright (C) 2016 by authors and Scientific Research Publishing Inc.

This work is licensed under the Creative Commons Attribution International License (CC BY). http://creativecommons.org/licenses/by/4.0/

c) (i) 0pen Access

\begin{abstract}
Metal nanostructures have been of great research interest in recent years due to their physicochemical, plasmonic properties and potential applications. A lot of work has been done on the controlled synthesis of metal nanostructures for various applications. In this review, we try to focus on recent developments in synthesis and applications of metal nanostructures. Firstly, we summarized different preparation methods and then briefly explained their potential applications.
\end{abstract}

\section{Keywords}

\section{Surface Plasmon Resonance (SPR), Metal Nanostructures, Plasmonic Applications}

\section{Introduction}

In recent years, the increasing number of published papers shows great interest of engineers and scientists for the importance of metal nanoparticles (NPs) such as silver (Ag), gold (Au) and copper (Cu) etc., because of their physicochemical properties, nano meter (nm) size and surface plasmon behavior [1] [2]. These metal NPs are used in catalysis, electronics for circuit development and as self-assembled new nanostructure materials, but only few show different sets of applications with light interaction. The interaction of light in a field with metal nanostructures is called as plasmonics [3]-[7]. The plasmonic nanostructure materials are defined by means of their strong interaction with incident light and free electrons, where metal nanostructures act as a source to convert light into localized electric field (electromagnetic excitations coupled with collective oscillations of free elec-

\footnotetext{
*Corresponding author.
} 
trons) in metals [8], and called as localized surface plasmon. Incident light can work more effectively with strictly controlled size and shape of metal nanostructures [4] [9]. Nanoplasmonic research is successfully gaining interest due to its various worth seeing applications, such as super lenses, surface enhanced Raman spectroscopy (SERS), single molecule spectroscopy [10]-[14], plasmon-enhanced fluorescence, nanoscale lasing, enhancement of non-linear optical signals, quantum computing, plasmon assisted photo lithography, photocatalysis, light harvesting, biochemical sensing and possibly conversion of solar to chemical energy with plasmonic metal nanostructures [15]-[25]. In last few decades, Au and Ag nanostructures have been prepared chemically on a large scale for plasmonic applications. Ag is 50 times cheaper than Au and became a good candidate in plasmonics due to its unique and convenient physicochemical properties for the next generation plasmonic technologies [26]-[28]. It is to be noted that plasmonics restrict to a coupling between electromagnetic excitation and metal nanostructure for the generation of surface plasmon and do not show plasmonic functions in the absence of incident light. Nanoplasmonic is quite unique as different sizes of nanostructures from 10 to $100 \mathrm{~s}$ of nanometers can be used which act as a link between nano and micrometer levels. Thus, plasmonics is a new subfield of nanotechnology which has ambition to understand the control of light with metal nanostructure in innovative approach.

The self-assembly of metal nanoparticles into small clusters, provides suitability to control and tune their optical properties by coupling surface plasmon of nanoparticles and enhance the electric field in between the particles gaps. These gaps in self-assembled nanostructures with high intensity field are known as hot spots. The enhancement of electric field is very important in terms of optical and chemical properties of nanoparticles as plasmonic properties are strongly influenced by electric field. We can control the self-assembly of nanostructures by varying the number of nanoparticles in a cluster or the size and shape of individual nanoparticles for the achievement of our required plasmonic applications. The number of scientific research publications on plasmonic nanostructures is rapidly increasing and expected to be continuing in the near future [29].

\section{Preparation of Metal Nanostructures}

Various methods are adopted for the preparation of metal nanostructures that should be ideally controllable regarding shape and size, cheap, environment friendly, and high product yield with less waste products. Figure 1 summarizes various preparation methods of metal nanostructures.

Metal nanostructures show high abundance of plasmon excitation for example scientists are showing much interest in Ag nanostructures due to plasmon resonance in the range of visible spectrum and used in various potential technologies. Here, we will discuss all synthetic processes in reference mostly of Ag, as an example.

\subsection{Chemical and Photochemical Synthesis}

The optical properties of metal nanostructures are highly dependent on their size and shape. The controlled morphology of nanostructures is an important factor which has strong impacts on their unique plasmonic properties. Until now, various methods are adopted for the preparation of controlled size and shape of nanostructures

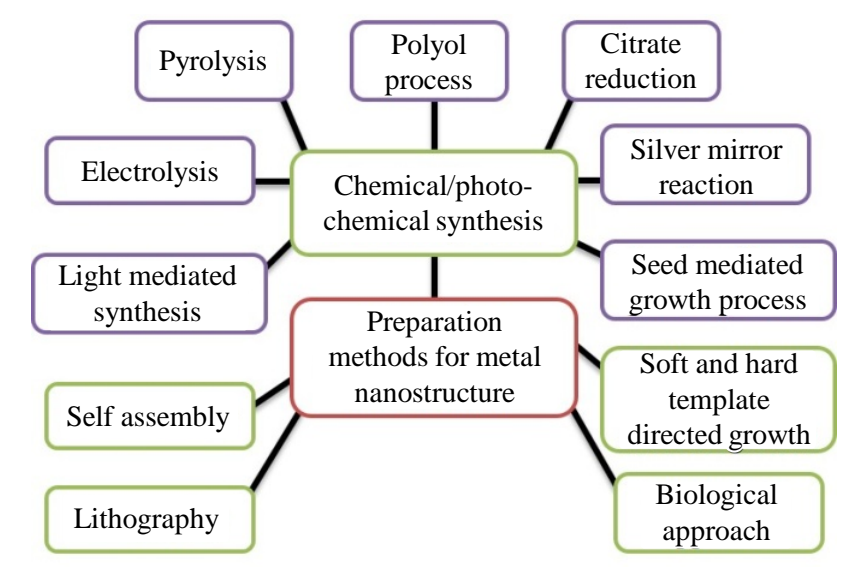

Figure 1. Various methods for synthesis of metal nanostructures. 
[30]-[32]. In general, metal/ $\mathrm{Ag}^{+}$salt precursor is mixed with reducing agent in the presence of stabilizing agent and control the size and shape of metal nanostructures. Past research publications show that silver nitrate, as a precursor, has been abundantly used due to its cheap price and easy availability. Various reducing agents such as sodium citrate, sodium borohydride and alcohols are widely used to reduce metal/ $\mathrm{Ag}^{+}$ions present in solution into metal/Ag atoms which combine to make aggregates and finally become nanostructures [33]-[35]. On the other hand, stabilizing agents are introduced to control and stabilize the required morphology of metal nanostructures. While, in photochemical synthesis, a variety of light irradiation methods are adopted to synthesize metal nanostructures. Following is the detail of chemical/photochemical synthetic processes.

\subsubsection{Light Mediated Synthesis}

In this technique, light irradiation is applied to produce nano structures. For example, laser ablation or direct laser irradiation on an aqueous solution of metal salt in the presence of surfactant to fabricate specific shape and size distribution of metal nanoparticles where source of light works as a reducing agent [36] [37]. Laser light is also used to modify metal nanoparticles by simple melting such as Ag nanospheres into Ag nanoplates [38]-[43] it is known as tailoring process with light. Laser light mediated synthesis is continuing its success for generating highly desirable and well controlled metal nanostructures.

\subsubsection{Electrolysis and Pyrolysis}

There are few scientific reports available, describing use of electrochemical approach for the synthesis of metal nanoparticles. For example spherical shaped Ag nanoparticles were synthesized with an average size of $10 \mathrm{~nm}$ by reducing $\mathrm{Ag}^{+}$ions in the presence of poly vinyl pyrrolidone (PVP) using electrochemical method, where titanium (Ti) electrode worked as a cathode and platinum (Pt) plate with $2 \mathrm{~cm}$ diameter worked as an anode. Ag nanoparticles are also synthesized by adopting another method of spray pyrolysis in which an average grain size of $100 \mathrm{~nm}$ of Ag nanopowder was synthesized. Among other chemical synthesis, electrolysis and pyrolysis are considered environmental friendly processes as no harmful or toxic reducing agents are used to produce nanostructures [44] [45].

\subsubsection{Citrate Reduction}

One of the popular methods to synthesize Ag colloidal solutions is citrate reduction of $\mathrm{Ag}^{+}$ions as we do not need comprehensive laboratory training skills [46]-[48]. First time, Lee and Meisel introduced this method in 1982 [49]. Generally, Ag nanoparticles are formed, when a calculated amount of sodium citrate is added in an aqueous solution of silver nitrate at boiling and wait for at least $1 \mathrm{~h}$. This is a very simple method but did not produce confined size of nanoparticles. The synthesized product shows variety of sizes in the range of $20-600$ $\mathrm{nm}$. However, $\mathrm{pH}$ control is an important factor, as few shape controlled methods had been discussed by previous researchers by controlling $\mathrm{pH}$ values such as at $\mathrm{pH}=5.7$ triangular shape and $\mathrm{pH}=11.1$ spherical as well as rod like particles were formed [50] [51].

\subsubsection{Polyol Synthesis}

One of the well-known and commonly used methods to synthesize a wide range of size and shape of Ag nanostructures [52]-[56]. In general, Ag salt precursor and capping agents are introduced into polyols for the generation of nucleation and growth towards Ag nanostructure. Propylene glycol, 1,2-propylene glycol or 1,5-pentanediol are commonly used reducing agents which reduce $\mathrm{Ag}^{+}$ions present in the solution [57]. Reaction parameters such as temperature and concentrations are very important to overcome the possible control on the final reaction product.

\subsubsection{Seed Mediated Synthesis}

In recent years, another approach to synthesize metal nanoparticles gaining much attention is seed mediated synthesis in which nanocrystals work as seeds for further growth. This method has advantages on the control over the end product morphology [58]-[61]. For example Xia et al., in 2010, synthesized, Ag nanocubes by using spherical or cubic shaped single crystal seed for specific edge length from 30 - $200 \mathrm{~nm}$.

\subsubsection{Silver Mirror Reaction}

Justus von Liebig discovered silver mirror reaction in 1835 [62] which became much popular for depositing Ag 
metal on targets or solid surfaces. In this reaction, Tollen's reagent $\left[\mathrm{Ag}\left(\mathrm{NH}_{3}\right)_{2} \mathrm{OH}\right]$ is reduced by sugar or any aldehyde containing compound for generating Ag (Equation (1)):

$$
\mathrm{RCHO}+2\left[\mathrm{Ag}\left(\mathrm{NH}_{3}\right)_{2}\right]^{+}+2 \mathrm{OH}^{-} \rightarrow \mathrm{RCOOH}+2 \mathrm{Ag}+4 \mathrm{NH}_{3}+\mathrm{H}_{2} \mathrm{O}
$$

Successful reaction shows shiny layer formation on the inner side of the reaction container due to the silver deposition. Silver mirror reaction is mostly employed for the detecting aldehyde group in schools [63].

\subsection{Soft and Hard Template Mediated Synthesis}

Template based synthesis has been used to prepare specific shape and size of nanostructures which highly depend upon the selected template [64] [65]. There are two types of template; soft and hard templates. Commonly, surfactant molecules work as a soft templates and form at critical micelle concentration (CMC). Porous anodic aluminum oxide (AAO) membrane could be a good example of hard templates. These micelle and reverse micelles structures present in the solutions are responsible for the shape and size of final product. Previously published research work shows that soft template assisted methods have been involved in preparation of metal nanostructures of various shapes and sizes such as Ag nanowires [66]-[68], nanorods [69]-[71], hollow spheres, nanoplates [72]-[76] etc. Based on properties, surfactants can be classified as ionic surfactants \{e.g., cetyltrimethylammonium bromide (CTAB) [77]-[82], octadecyltrimethylammonium chloride (OTAC), di sodium (2-ethylhexyl) sulfosuccinate (Na (AOT)) [83]-[85] and sodium dodecylsulfate (SDS) [86]\}, nonionic surfactants \{e.g., oleic acid (OA) [87] [88], oleylamine (OAM) [89] [90], trioctylphosphine (TOP) [91] and trioctylphosphine oxide (TOPO)\} and polymer surfactants \{e.g., poly(vinyl pyrrolidone) (PVP) [92]-[99], poly(vinyl alcohol) (PVA) [100] and poly(ethylene oxide) [101]\}. Template assisted synthesis has some advantages such as final product is in well dispersed form due to reduction in the formation of aggregates [102]-[104], reaction conditions are mild as well as benign route in respect of reactants and solvents. However, still there is need to improve the parameters to achieve the desired shape and size of nanostructures which is a challenge for researchers.

\subsection{Lithographic Approach}

Lithography is concerning with the study and application for the fabrication of nanometer structure with at least one dimension from 1 to $100 \mathrm{~nm}$ scale. Unlike the liquid based process, lithography, process of deposition and other nano-fabrication techniques provide controllable installation ability for metal nanostructures [105]. Many kinds of lithographic techniques have been presented by researchers such as optical lithography (OL), electron beam lithography (EBL) [106], scanning probe lithography (SPL), multiphoton lithography (MPL) etc. and applied as per requirements for example EBL technique is used to fabricate mask by depositing Ag nanostructure on a substrate [107].

\subsection{Self-Assembly of Metal Nanoparticles}

Self-assembly of metal nanoparticles can be distinguished on the basis of shapes of individual nanoparticles, methods used for self-assembly and the nature of forces involved for self-assembly of nanoparticles. Nanoparticles are the basic building blocks for assisted self-assembly process [108]-[110]. This process can generate the formation of large sized final product such as nanosheets at microscale in comparison with other methods [111]. One another fast strategical approach for self-assembly of stable metal nanoparticles is DNA linkage [112][115]. Self-assembly assisted by DNA has been adopted recently to develop systematically arranged plasmonic nanoparticles into chain, triangular shape, 3D lattices and Janus nanoclusters [116]-[121]. For example, fabrication of free-standing monolayered Au nanoparticle super lattice sheet formation with DNA linkage. Direct interaction of nanoparticles in solutions such as major driving forces, attractive and repulsive forces impact on the whole self-assembly process which can be discussed as hydrophobic, electrostatic, hydrogen bonding and biospecific interaction of self-assembly of metal nanoparticles.

\subsection{Hydrothermal Process}

Hydrothermal process is simple and has been widely used for the synthesis of different kinds of nanostructures [122]-[124]. Usually, high temperature is required to proceed it. For example, Yan et al., synthesized triangular shaped Ru nanoplates with thickness $\sim 3 \mathrm{~nm}$ using $\mathrm{RuCl}_{3} \cdot \mathrm{H}_{2} \mathrm{O}$ and $\mathrm{HCHO}$ (40 wt\%) in the presence of PVP at 
$160^{\circ} \mathrm{C}$ for $4 \mathrm{~h}$. It was also noticed that only change in the concentration of Ru salt and PVP, irregular shape formed with thickness $\sim 1.5 \mathrm{~nm}$. On the other hand, when Ru salt was replaced with silver nitrate, triangular shaped Ag nanoplates were formed with sharp and curved corners in the presence of PVP at $160^{\circ} \mathrm{C}$ for $6 \mathrm{~h}$.

\subsection{Biological Approach}

Recently, it has been noticed that living microorganisms such as bacteria, fungi and plants have great potential for the synthesis of metal nanoparticles such as cadmium sulfide (CdS) [125], Ti/Ni, titanate [126], zirconia [127], Au [128] [129] and Ag [130] [131]. The use of microorganisms is environmental friendly and benign synthesis route for which provides good control over size distribution of nanostructures. For example, Ag nanostructures were synthesized using bacteria with size less than $200 \mathrm{~nm}$.

\section{Potential Applications}

\subsection{Photocatalysis}

Novel functional nanomaterials have gained much attention due to their unique catalytic, optical, electronic, magnetic, and mechanical properties. In present years, whole world is focused to overcome near future problems such as environmental pollution, energy conversion, and the production of organic compound which compelled researchers to develop novel catalysts, that can catalyze desirable chemical transformations, using light. Plasmonic metal nanostructures with controlled morphology, shape, and pore structure have a higher surface area, which leads to the increased catalytic activity. So, there is an ever-increasing interest to design novel catalysts and establish a structure-activity relationship for the understanding of reaction mechanism. This allows researchers to develop a wide range of suitable catalysts for energy, environment remediation, and organic synthesis applications. Until now, a lot of work has been done in searching cost effective, sustainable and green energy sources to meet global energy requirements for current environmental contamination and the growing threat of present energy crisis. An environmental friendly renewable energy resource such as solar energy to remove organic pollutants in the presence of highly effective photocatalysts has been regarded as the ultimate solution for green chemical processes and hydrogen production [132].

On the bases of photocatalysis science, there are two types of photocatalytic reactions i.e. homogeneous photocatalysis and heterogeneous photocatalysis. The most prominent features of the photocatalytic system are the required band gap, suitable morphology, high surface area, stability and reusability [133]-[136]. A number of metal oxides are known as photocatalysts such as oxides of vanadium, chromium, titanium, zinc, tin, and cerium. During the reaction process, a metal oxide is activated with UV light, visible light or a combination of both that depend upon its light absorption range and as a result, photo excited electrons are moved from the valence band (VB) to conduction band (CB) and form an electron/hole pair $\left(\mathrm{e}^{-} / \mathrm{h}+\right)$. This photo-generated pair $(\mathrm{e}-/ \mathrm{h}+)$ is able to reduce and/or oxidize a compound adsorbed on the surface of photocatalyst. More recently, it is investigated that defected metal oxide could perform well in visible light by using band gap engineering to create small band gap as shown in Figure 2. The favorable combination of electronic structure, light absorption properties, charge transport characteristics and excited lifetimes of metal oxides has made it possible for their application as

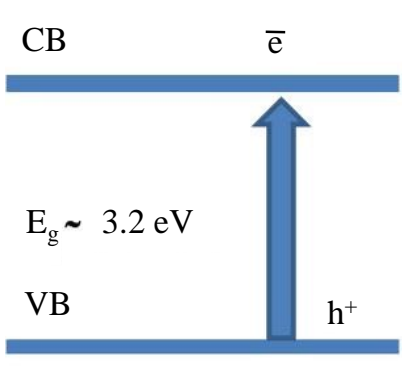

UV light active MO

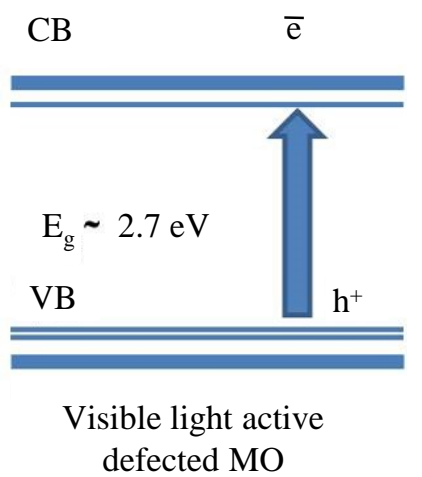

defected MO

Figure 2. Photo excitation of UV light active and visible light active metal oxides (MO). 
photocatalyst [133]-[137]. However, it is particularly difficult to find enough stable semiconductor system with a suitable band gap for visible absorption, required for driving subsequent redox reactions. Metal oxides such as $\left(\mathrm{TiO}_{2}, \mathrm{ZnO}, \mathrm{SnO}_{2}\right.$ and $\mathrm{CeO}_{2}$ ) have been widely investigated for photocatalytic applications [138]; however, the relatively wide band gap limits their photocatalytic applications because UV light only accounts for $4 \%$ of the total solar spectrum [139].

Until now, varieties of photocatalyst for water splitting have been reported but most of these are only active under UV light irradiation and only a few have been demonstrated to operate under visible light up to a wavelength of $500 \mathrm{~nm}$ [140]. Recently, Chengsi Pan et al. developed photocatalyst that is working over a wider range of visible light spectrum approximately $600 \mathrm{~nm}$ [141]. On the other hand, surface modification along with combination of suitable co-catalysts for enhancing photocatalytic reactions [142], self-assembly and growth mechanism are equally important factors as well as designing new strategies for the development of novel nanomaterials. Thus, scalable, cost-effective routes to synthesize novel nanostructured, visible-light responsive catalyst with narrow bandgap and a larger wavelength range are desired which accounts for $43 \%$ of the spectrum of sunlight.

\subsection{Surface Enhanced Raman Scattering (SERS)}

SERS is a surface sensitive powerful technique used to detect various molecules because of its high sensitivity and selectivity [143]-[150]. Metal plasmonic nanostructures such as Ag and Au have been known for more effective SERS substrates that can increase the Raman Scattering of the molecules [151]-[154]. Plasmonic nanostructures with sharp corners are familiar for keeping SERS activities that can increase electromagnetic field (E-field) and create "hot spots" [155] [156]. For example, Xia et al. described recently the importance of sharpness of metal nanostructures in SERS such as the signal intensity of 4-mercapto-pyridine for triangular shape and hexagonal Pd nanoplate was 4.3 and 3.4 times that of Pd cuboctahedra [157]. By controlling the sharp corners of the nanostructures, SERS signals can be increased; however, the stability of the sharpness is an issue. To overcome this problem, bimetallic nanostructures such as Pd-Ag core-shell were synthesized for SERS applications [158] that showed relatively stable signals.

More recently, research has been carried out to examine the hot spot (area with high E-field enhancement) in single particle or dimers to determine the contribution of hot spot SERS signal enhancement factor [159]-[166]. On the other hand, theoretically, the maximum amplitude of the normalized E-field of Ag dimer with $2 \mathrm{~nm}$ gap distance is nearly 25 and 200 times that of Ag nanoplate and spherical particle, respectively. Moreover, it was observed that SERS signals on metal self-assembled nanostructures (Ag) could be regulated by controlling the structural orientation of metals.

\subsection{Localized Surface Plasmon Resonance (LSPR) Detection/Sensing}

Detection and sensing of molecules is one of the best applications of plasmonic structures and was commercially launched as propagation surface plasmons (PSPs) on metal films. These metal films are chemically used for selected binding of target molecules such as DNA or proteins. After binding, the dielectric charge near the surface of metal films is generated. Such bindings could be monitored between the metal film and exciting source for generation of PSPs. Still, on behalf of this technique, a large number of instruments are available in the market and used for biological science [167]. PSPs technique has been extended to LSPR for detecting and sensing metal nanoparticles. When the dielectric environment change by introducing the detecting molecules, the resonance frequency of LSPR shifts and that is the main idea for sensing molecules [168]-[171]. In more recent advancements, much focus is to increase the LSPR sensitivity of metal nanostructures. For example, when the spectral overlapping between LSPR and the molecular electronic resonance takes place, a strong resonance coupling can be observed [172]. It is also observed that the morphological changes in the nanostructures are very important factor which strongly correspond with LSPR. Recently, the development of colorimetric indicators depending on time and temperature are praise able [173].

\subsection{Photo-Thermal Therapy}

Metal nanostructures, could be a dominating nominee for photo-thermal therapy due to strong LSPR absorption especially in the Near Infra-red (NIR) region, photo-thermal stability and biocompatibility factors [174]-[180]. 
For example, palladium (Pd) nanosheets in an aqueous solution were illuminated by NIR laser light and monitored for the NIR photothermal efficiencies at various temperatures. It was observed that the temperature increased from $28^{\circ} \mathrm{C}$ to $48.7^{\circ} \mathrm{C}$ after $10 \mathrm{~min}$. NIR laser irradiation, when Pd nanosheets were present into the solution. In contrast, the temperature of $1 \mathrm{ml}$ aqueous solution without Pd nanosheets raised only $0.5^{\circ} \mathrm{C}$ by NIR laser irradiation. This technique was applied to the liver cancer cells and the results were remarkable as nearly $100 \%$ cancer cells were killed just in 5 min. laser irradiation. It was also observed that the photo-thermal stability of Pd nanosheets was good as compared to $\mathrm{Au}$ and $\mathrm{Ag}$ when irradiated with NIR laser for $30 \mathrm{~min}$. For further increase in photo-thermal stability of Pd nanosheets, a coating with Ag thin layer was preferable. Other than Pd nanosheets, it has been reported that Au nanoprism showed excellent photo-thermal stability under longer NIR laser (wavelength $1064 \mathrm{~nm}$ ) irradiation time which is a good point as Infra-red (IR) light could have high tissue penetration and lower optical absorption by blood and soft tissues [176]-[181].

\subsection{Surface Enhanced Fluorescence (SEF)}

Fluorescence technique is used in many applications such as microscopy imaging, optical devices and medical diagnosis. Scientists show great interest to improve the fluorescence sensitivity of fluorophore substrates; however, it becomes more interesting when limited to a single molecule due to the requirement of many potential applications. For this purpose, SEF technique is used. It is based upon the emission of resonant molecules in the locality of emitters [182]-[184]. SEF is highly dependent on near field coupling between excited states fluorophores and surface modes. Especially, surfaces of plasmonic nanostructure with localized surface plasmons are efficient SEF substrates. Likewise in SERS, molecular distance from plasmonic nanostructures affects the SEF experiments because of the interaction of molecules and nanoparticles [185] [186].

\subsection{Surface Based Electronic Devices}

The main theme on which molecular sensors work is the molecular absorption. Molecular absorption has impact on the emission peak, position and intensity of plasmon absorption. Optical integration and electronic circuiting could be helpful in making high speed, small size computer microprocessors [187] [188]. On the other hand, surface plasmons are important as acknowledged for transmitting information on computer chips. Plasmonic nanostructures are helpful in supporting high frequencies $(100 \mathrm{THz})$ as compared to simple conventional wires $(10 \mathrm{GHz})$. The ability of plasmonic nanostructures to work on high frequency distinguishes them for developing useful electronics such as plasmonstors [189]. In general, lithographic techniques are used in developing electronic devices based on plasmonic circuits [190]-[193]. Lithographic techniques are also helpful to overcome the problems in terms of location, geometry and orientation. Surface plasmons are material sensitive for propagation and supportive for measuring thickness of monolayers on colloid films. Many companies like Biacore have made instruments based on this principle. A team of Korean scientists in 2009 discovered a method for improving efficiency of organic light emitting diodes [194].

\subsection{Other Applications}

As discussed before, metal plasmonic nanostructures are promising materials for potential applications. Many new applications are rising in wide potential areas [195]-[199]. New advanced applications could be in the field of lasers, super lenses, active plasmonics, photovoltaics [200]-[211], phase changing materials [212] and polymers [213], etc. Figure 3 describes a flow sheet diagram of various potential applications of metal nanostructures.

\section{Conclusion}

The concept of developing and organizing metal nanoparticles into plasmonic nanostructures is awesome which supports to establish a new way of knowledge towards metal nanostructure interactions in solution, synthesis of new materials with various plasmonic properties and functional nanomaterials. In recent years, research work on plasmonic metal nanostructures shows great interest of scientists and provides a strong hold over the control of light. Herein, we explained various preparation methods and potential applications of metal nanostructures such as photocatalysis, SERS, photothermal therapy, LSPR based sensing and detection, plasmonic based electronic devices and SEF technique. However, there is still room for improvements and big challenges that need to be 


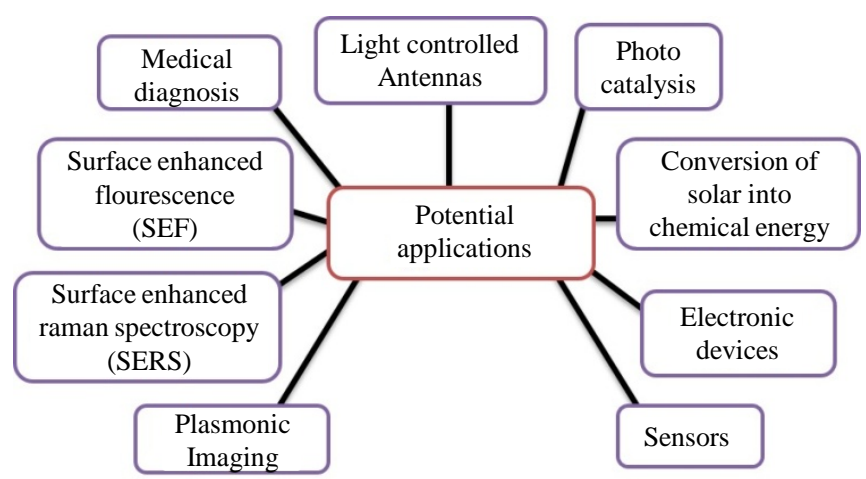

Figure 3. Flow diagram of various potential applications of metal nanostructures.

discussed in consideration of new important applications. The fast growing research developments in the field of plasmonics will open a new era for generating small and ultrafast devices.

\section{References}

[1] Rao, C.N.R., Kulkarni, G.U., Thomas, P.J. and Edwards, P.P. (2002) Size Dependent Chemistry: Properties of Nanocrystals. Chemistry A-European Journal, 8, 28-35. http://dx.doi.org/10.1002/1521-3765(20020104)8:1<28::AID-CHEM28>3.0.CO;2-B

[2] Stockman, M.I. (2011) Nanoplasmonics: The Physics behind the Application. Physics Today, 64, 39-44. http://dx.doi.org/10.1063/1.3554315

[3] Shalaev, V.M. (2008) Transforming Light. Science, 322, 384-386. http://dx.doi.org/10.1126/science.1166079

[4] Brongersma, M.L. and Shalaev, V.M. (2010) Applied Physics: The Case for Plasmonics. Science, 328, 440-441. http://dx.doi.org/10.1126/science.1186905

[5] Gramotnev, D.K. and Bozhevolnyi, S.I. (2010) Plasmonics beyond the Diffraction Limit. Nature Photonics, 4, 83-91. http://dx.doi.org/10.1038/nphoton.2009.282

[6] Lal, S., Link, S. and Halas, N.J. (2007) Nano-Optics from Sensing to Waveguiding. Nature Photonics, 1, 641-648. http://dx.doi.org/10.1038/nphoton.2007.223

[7] Schuller, J.A., Barnard, E.S., Cai, W., Jun, Y.C., White, J.S. and Brongersma, M.L. (2010) Plasmonics for Extreme Light Concentration and Manipulation. Nature Materials, 9, 193-204. http://dx.doi.org/10.1038/nmat2630

[8] Moskovits, M. (2001) Near-Field Optics and Surface Plasmonpolaritons. Kawata, S., Ed., Springer, Berlin.

[9] Barnes, W.L., Dereux, A. and Ebbesen, T.W. (2003) Review Article Surface Plasmon Subwavelength Optics. Nature, 424, 824-830. http://dx.doi.org/10.1038/nature01937

[10] Brus, L. (2008) Noble Metal Nanocrystals: Plasmon Electron Transfer Photochemistry and Single Molecule Raman Spectroscopy. Accounts of Chemical Research, 41, 1742-1749. http://dx.doi.org/10.1021/ar800121r

[11] Jiang, J., Bosnick, K., Maillard, M. and Brus, L. (2003) Single Molecule Raman Spectroscopy at the Junctions of Large Ag Nanocrystals. Journal of Physical Chemistry B, 107, 9964-9972. http://dx.doi.org/10.1021/jp034632u

[12] Nie, S. and Emory, S.R. (1997) Probing Single Molecules and Single Nanoparticles by Surface Enhanced Raman Scattering. Science, 275, 1102-1106. http://dx.doi.org/10.1126/science.275.5303.1102

[13] Kühn, S., Håkanson, U., Rogobete, L. and Sandoghdar, V. (2006) Enhancement of Single Molecule Fluorescence Using a Gold Nanoparticle as an Optical Nanoantenna. Physical Review Letters, 97, Article ID: 017402. http://dx.doi.org/10.1103/PhysRevLett.97.017402

[14] Atwater, H.A. and Polman, A. (2010) Plasmonics for Improved Photovoltaic Devices. Nature Materials, 9, $205-213$. http://dx.doi.org/10.1038/nmat2629

[15] Moskovits, M. (2005) Surface Enhanced Raman Spectroscopy: A Brief Retrospective. Journal of Raman Spectroscopy, 36, 485-496. http://dx.doi.org/10.1002/jrs.1362

[16] Lakowicz, J.R., Ray, K., Chowdhury, M., Szmacinski, H., Fu, Y., Zhang, J. and Nowaczyk, K. (2008) Plasmon Controlled Fluorescence: A New Paradigm in Fluorescence Spectroscopy. Analyst, 133, 1308-1346. http://dx.doi.org/10.1039/b802918k

[17] Zakharko, Y., Nychyporuk, T., Bonacina, L., Lemiti, M. and Lysenko, V. (2013) Plasmon Enhanced Nonlinear Optical 
Properties of SiC Nanoparticles. Nanotechnology, 24, Article ID: 055703. http://dx.doi.org/10.1088/0957-4484/24/5/055703

[18] Zhou, W., Dridi, M., Suh, J.Y., Kim, C.H., Co, D.T., Wasielewski, M.R., Schatz, G.C. and Odom, T.W. (2013) Lasing Action in Strongly Coupled Plasmonic Nanocavity Arrays. Nature Nanotechnology, 8, 506-511. http://dx.doi.org/10.1038/nnano.2013.99

[19] Shao, D.B. and Chen, S.C. (2005) Surface Plasmon Assisted Nanoscale Photolithography by Polarized Light. Applied Physics Letters, 86, Article ID: 253107. http://dx.doi.org/10.1063/1.1951052

[20] Pillai, S., Catchpole, K.R., Trupke, T. and Green, M.A. (2007) Surface Plasmon Enhanced Silicon Solar Cells. Journal of Applied Physics, 101, Article ID: 093105. http://dx.doi.org/10.1063/1.2734885

[21] Hou, W. and Cronin, S.B. (2013) A Review of Surface Plasmon Resonance Enhanced Photocatalysis. Advanced Functional Materials, 23, 1612-1619. http://dx.doi.org/10.1002/adfm.201202148

[22] Stewart, M.E., Anderton, C.R., Thompson, L.B., Maria, J., Gray, S.K., Rogers, J.A. and Nuzzo, R.G. (2008) Nanostructured Plasmonic Sensors. Chemical Reviews, 108, 494-521. http://dx.doi.org/10.1021/cr068126n

[23] Fang, N., Lee, H. and Zhang, X. (2005) Sub Diffraction Limited Optical Imaging with a Silver Superlens. Science, 308, 534-537. http://dx.doi.org/10.1126/science.1108759

[24] Kamat, P.V. (2002) Photophysical, Photochemical and Photocatalytic Aspects of Metal Nanoparticles. Journal of Physical Chemistry B, 106, 7729-7744. http://dx.doi.org/10.1021/jp0209289

[25] Tian, Y. and Tatsuma, T. (2005) Mechanisms and Applications of Plasmon Induced Charge Separation at $\mathrm{TiO}_{2} \mathrm{Films}$ Loaded with Gold Nanoparticles. Journal of the American Chemical Society, 127, 7632-7637. http://dx.doi.org/10.1021/ja042192u

[26] Wiley, B., Sun, Y. and Xia, Y. (2007) Synthesis of Silver Nanostructures with Controlled Shapes and Properties. Accounts of Chemical Research, 40, 1067-1076. http://dx.doi.org/10.1021/ar7000974

[27] Pyayt, A.L., Wiley, B., Xia, Y., Chen, A. and Dalton, L. (2008) Integration of Photonic and Silver Nanowire Plasmonic Waveguides. Nature Nanotechnology, 3, 660-665. http://dx.doi.org/10.1038/nnano.2008.281

[28] Rang, M., Jones, A.C., Zhou, F., Li, Z.Y., Wiley, B.J., Xia, Y. and Raschke, M.B. (2008) Optical Near Field Mapping of Plasmonic Nanoprisms. Nano Letters, 8, 3357-3363. http://dx.doi.org/10.1021/nl801808b

[29] Wang, L., Xu, L., Kuang, H., Xu, C. and Kotov, N.A. (2012) Dynamic Nanoparticle Assemblies. Accounts of Chemical Research, 45, 1916-1926. http://dx.doi.org/10.1021/ar200305f

[30] Sun, Y. and Xia, Y. (2002) Shape Controlled Synthesis of Gold and Silver Nanoparticles. Science, 298, $2176-2179$. http://dx.doi.org/10.1126/science.1077229

[31] Tao, A., Sinsermsuksakul, P. and Yang, P. (2006) Polyhedral Silver Nanocrystals with Distinct Scattering Signatures. Angewandte Chemie International Edition, 45, 4597-4601. http://dx.doi.org/10.1002/anie.200601277

[32] Korte, K.E., Skrabalak, S.E. and Xia, Y. (2008) Rapid Synthesis of Silver Nanowires through a CuCl or $\mathrm{CuCl}_{2} \mathrm{Me}^{-}$ diated Polyol Process. Journal of Materials Chemistry, 18, 437-441. http://dx.doi.org/10.1039/B714072J

[33] Yee, C., Scotti, M., Ulman, A., White, H., Rafailovich, M. and Sokolov, J. (1999) One Phase Synthesis of Thiol Functionalized Platinum Nanoparticles. Langmuir, 15, 4314-4316. http://dx.doi.org/10.1021/la9814283

[34] Teranishi, T., Hosoe, M., Tanaka, T. and Miyake, M. (1999) Size Control of Monodispersed Pt Nanoparticles and Their 2D Organization by Electrophoretic Deposition. Journal of Physical Chemistry, 103, 3818-3827. http://dx.doi.org/10.1021/jp983478m

[35] Wu, X., Redmond, P.L., Liu, H., Chen, Y., Steigerwald, M. and Brus, L. (2008) Photovoltage Mechanism for Room Light Conversion of Citrate Stabilized Silver Nanocrystal Seeds to Large Nanoprisms. Journal of American Chemical Society, 130, 9500-9506. http://dx.doi.org/10.1021/ja8018669

[36] Qazi, U.Y., Kajimoto, S. and Fukumura, H. (2014) Effect of Sodium Dodecyl Sulfate on the Formation of Silver Nanoparticles by Biphotonic Reduction of Silver Nitrate in Water. Chemistry Letters, 43, 1693-1695. http://dx.doi.org/10.1246/cl.140617

[37] Lim, P.Y., Liu, R.S., She, P.L., Hung, C.F. and Shih, H.C. (2006) Synthesis of Ag Nanospheres Particles in Ethylene Glycol by Electrochemical Assisted Polyol Process. Chemical Physics Letters, 420, 304-308. http://dx.doi.org/10.1016/j.cplett.2005.12.075

[38] Zhang, J., Li, S., Wu, J., Schatz, G. and Mirkin, C. (2009) Plasmon Mediated Synthesis of Silver Triangular Bipyramids. Angewandte Chemie International Edition, 48, 7927-7931. http://dx.doi.org/10.1002/ange.200903380

[39] Kabashin, A.V., Delaporte, P., Pereira, A., Grojo, D., Torres, R., Sarnet, T. and Sentis, M. (2010) Nanofabrication with Pulsed Lasers. Nanoscale Research Letters, 5, 454-463. http://dx.doi.org/10.1007/s11671-010-9543-z

[40] Zheng, X., Xu, W., Corredor, C., Xu, S., An, J., Zhao, B. and Lombardi, J.R. (2007) Laser Induced Growth of Monodisperse Silver Nanoparticles with Tunable Surface Plasmon Resonance Properties and a Wavelength Self Limiting 
Effect. Journal of Physical Chemistry C, 111, 14962-14967. http://dx.doi.org/10.1021/jp074583b

[41] Xue, C., Metraux, G.S., Millstone, J.E. and Mirkin, C.A. (2008) Mechanistic Study of Photomediated Triangular Silver Nanoprism Growth. Journal of American Chemical Society, 130, 8337-8344. http://dx.doi.org/10.1021/ja8005258

[42] Jin, R., Cao, Y., Mirkin, C.A., Kelly, K.L., Schatz, G.C. and Zheng, J.G. (2001) Photoinduced Conversion of Silver Nanospheres to Nanoprisms. Science, 294, 1901-1903. http://dx.doi.org/10.1126/science.1066541

[43] Haro-Poniatowski, E., Batina, N., Acosta-Garca, M.C., Pohl-Alfaro, M.A., Castillo-Ocampo, P., Ricolleau, C. and Fort, E. (2007) UV Laser Irradiation Effects on Silver Nanostructures. Radiation Effects and Defects in Solids, 162, 491-499. http://dx.doi.org/10.1080/10420150701472213

[44] Sharma, V.K., Yngard, R.A. and Lin, Y. (2009) Silver Nanoparticles: Green Synthesis and Their Antimicrobial Activities. Advances in Colloid and Interface Science, 145, 83-96. http://dx.doi.org/10.1016/j.cis.2008.09.002

[45] Qiaoxin, Z., Hao, L., Xiaohui, W., Xiaoliang, S. and Xinglong, D. (2009) Fabrication and Characterization of Nano Silver Powder Prepared by Spray Pyrolysis. Journal of Wuhan University of Technology, Materials Science Edition, 24, 871-874. http://dx.doi.org/10.1007/s11595-009-6871-X

[46] Koh, A.L., Bao, K., Khan, I., Smith, W.E., Kothleitner, G., Nordlander, P., Maier, S.A. and McComb, D.W. (2009) Electron Energy Loss Spectroscopy (EELS) of Surface Plasmons in Single Silver Nanoparticles and Dimers: Influence of Beam Damage and Mapping of Dark Modes. ACS Nano, 3, 3015-3022. http://dx.doi.org/10.1021/nn900922z

[47] Camden, J.P., Dieringer, J.A., Wang, Y., Masiello, D.J., Marks, L.D., Schatz, G.C. and Duyne, R.P.V. (2008) Probing the Structure of Single Molecule Surface Enhanced Raman Scattering Hot Spots. Journal of American Chemical Society, 130, 12616-12617. http://dx.doi.org/10.1021/ja8051427

[48] Pillai, Z.S. and Kamat, P.V. (2004) What Factors Control the Size and Shape of Silver Nanoparticles in the Citrate Ion Reduction Method? Journal of Physical Chemistry B, 108, 945-951. http://dx.doi.org/10.1021/jp037018r

[49] Lee, P.C. and Meisel, D. (1982) Adsorption and Surface Enhanced Raman of Dyes on Silver and Gold Sols. Journal of Physical Chemistry, 86, 3391-3395. http://dx.doi.org/10.1021/j100214a025

[50] Henglein, A. and Giersig, M. (1999) Formation of Colloidal Silver Nanoparticles: Capping Action of Citrate. Journal of Physical Chemistry B, 103, 9533-9539. http://dx.doi.org/10.1021/jp9925334

[51] Dong, X., Ji, X., Wu, H., Zhao, L., Li, J. and Yang, W. (2009) Shape Control of Silver Nanoparticles by Stepwise Citrate Reduction. Journal of Physical Chemistry C, 113, 6573-6576. http://dx.doi.org/10.1021/jp900775b

[52] Wiley, B., Sun, Y. and Xia, Y. (2007) Synthesis of Silver Nanostructures with Controlled Shapes and Properties. Accounts of Chemical Research, 40, 1067-1076. http://dx.doi.org/10.1021/ar7000974

[53] Xia, Y., Xiong, Y., Lim, B. and Skrabalak, S.E. (2009) Shape Controlled Synthesis of Metal Nanocrystals: Simple Chemistry Meets Complex Physics? Angewandte Chemie International Edition, 48, 60-103. http://dx.doi.org/10.1002/anie.200802248

[54] Tao, A., Sinsermsuksakul, P. and Yang, P. (2006) Polyhedral Silver Nanocrystals with Distinct Scattering Signatures. Angewandte Chemie International Edition, 45, 4597-4601. http://dx.doi.org/10.1002/anie.200601277

[55] Wiley, B.J., Wang, Z.L., Wei, J., Yin, Y., Cobden, D.H. and Xia, Y. (2006) Synthesis and Electrical Characterization of Silver Nanobeams. Nano Letters, 6, 2273-2278. http://dx.doi.org/10.1021/nl061705n

[56] Tao, A.R., Habas, S. and Yang, P. (2008) Shape Control of Colloidal Metal Nanocrystals. Small, 4, 310-325. http://dx.doi.org/10.1002/smll.200701295

[57] Sun, Y. and Xia, Y. (2002) Shape Controlled Synthesis of Gold and Silver Nanoparticles. Science, 298, 2176-2179. http://dx.doi.org/10.1126/science.1077229

[58] Zhang, Q., Li, W., Moran, C., Chen, J., Wen, L.P. and Xia, Y. (2010) Seed Mediated Synthesis of Ag Nanocubes with Controllable Edge Lengths in the Range of 30-200 nm and Comparison of their Optical Properties. Journal of American Chemical Society, 132, 11372-11378. http://dx.doi.org/10.1021/ja104931h

[59] Jana, N.R., Gearheart, L. and Murphy, C.J. (2001) Seed Mediated Growth Approach for Shape Controlled Synthesis of Spheroidal and Rod like Gold Nanoparticles Using a Surfactant Template. Advance Materials, 13, 1389-1393. http://dx.doi.org/10.1002/1521-4095(200109)13:18<1389::AID-ADMA1389>3.0.CO;2-F

[60] Pietrobon, B., McEachran, M. and Kitaev, V. (2008) Synthesis of Size Controlled Faceted Pentagonal Silver Nanorods with Tunable Plasmonic Properties and Self Assembly of These Nanorods. ACS Nano, 3, 21-26. http://dx.doi.org/10.1021/nn800591y

[61] Sun, Y., Yin, Y., Mayers, B.T., Herricks, T. and Xia, Y. (2002) Uniform Silver Nanowires Synthesis by Reducing $\mathrm{AgNO}_{3}$ with Ethylene Glycol in the Presence of Seeds and Poly(vinyl pyrrolidone). Chemistry of Materials, 14, 47364745. http://dx.doi.org/10.1021/cm020587b

[62] Liebigs, J. (1856) Ueber Versilberung und Vergoldung von Glas. Annalen der Chemie und Pharmacie, 98, $132-139$. http://dx.doi.org/10.1002/jlac.18560980112 
[63] Kemp, M. (1981) Silver Mirror. Journal of Chemical Education, 58, 655. http://dx.doi.org/10.1021/ed058p655.2

[64] Martin, C.R. (1994) Nanomaterials: A Membrane-Based Synthetic Approach. Science, 266, 1961-1966. http://dx.doi.org/10.1126/science.266.5193.1961

[65] Thomas, A., Goettmann, F. and Antonietti, M. (2008) Hard Templates for Soft Materials: Creating Nanostructured Organic Materials. Chemistry of Materials, 20, 738-755. http://dx.doi.org/10.1021/cm702126j

[66] Kryukov, A., Stroyuk, A., Zinchuk, N., Korzhak, A. and Kuchmii, S. (2004) Optical and Catalytic Properties of Ag S $^{2}$ Nanoparticles. Journal of Molecular Catalysis, 221, 209-221. http://dx.doi.org/10.1016/j.molcata.2004.07.009

[67] Zheng, X.W., Zhu, L.Y., Yan, A.H., Wang, X.J. and Xie, Y. (2003) Controlling Synthesis of Silver Nanowires and Dendrites in Mixed Surfactant Solutions. Journal of Colloid and Interface Science, 268, 357-361. http://dx.doi.org/10.1016/j.jcis.2003.09.021

[68] Zhang, J.L., Han, B.X., Liu, M.H., Liu, D.X., Dong, Z.X., Liu, J., Li, D., Wang, J., Dong, B.Z., Zhao, H. and Rong, L.X. (2003) Ultrasonication Induced Formation of Silver Nanofibers in Reverse Micelles and Small Angle X Ray Scattering Studies. Journal of Physical Chemistry B, 107, 3679-3683. http://dx.doi.org/10.1021/jp026738f

[69] Jana, N.R., Gearheart, L. and Murphy, C.J. (2001) Wet Chemical Synthesis of Silver Nanorods and Nanowires of Controllable Aspect Ratio. Chemical Communications, No. 7, 617-618. http://dx.doi.org/10.1039/b100521i

[70] Liu, Y., Chu, Y., Yang, L.K., Han, D.X. and Lu, Z.X. (2005) A Novel Solution Phase Route for the Synthesis of Crystalline Silver Nanowires. Material Research Bulletin, 40, 1796-1801. http://dx.doi.org/10.1016/j.materresbull.2005.05.005

[71] Ni, C.Y., Hassan, P.A. and Kaler, E.W. (2005) Structural Characteristics and Growth of Pentagonal Silver Nanorods Prepared by a Surfactant Method. Langmuir, 21, 3334-3337. http://dx.doi.org/10.1021/la046807c

[72] Maillard, M., Giorgio, S. and Pileni, M.P. (2003) Tuning the Size of Silver Nanodisks with Similar Aspect Ratios: Synthesis and Optical Properties. Journal of Physical Chemistry B, 107, 2466-2470. http://dx.doi.org/10.1021/jp022357q

[73] Zhang, W., Qiao, X. and Chen, J. (2007) Synthesis of Silver Nanoparticles Effects of Concerned Parameters in Water/Oil Microemulsion. Materials Science and Engineering B, 142, 1-15. http://dx.doi.org/10.1016/j.mseb.2007.06.014

[74] Chen, S.H. and Carroll, D.L. (2002) Synthesis and Characterization of Truncated Triangular Silver Nanoplates. Nano Letters, 2, 1003-1007. http://dx.doi.org/10.1021/nl025674h

[75] Yener, D.O., Sindel, J., Randall, C.A. and Adair, J.H. (2002) Synthesis of Nanosized Silver Platelets in Octylamine Water Bilayer Systems. Langmuir, 18, 8692-8699. http://dx.doi.org/10.1021/la011229a

[76] Zang, D.B., Song, C.X., Hu, Z.S. and Zhou, X.D. (2005) Synthesis of Silver Nanoparticles with Flake like Shapes. Material Letters, 59, 1760-1763. http://dx.doi.org/10.1016/j.matlet.2005.01.061

[77] Song, Y., Dorin, R.M., Garcia, R.M., Jiang, Y.B., Wang, H., Li, P., Qiu, Y., Swol, F.V., Miller, J.E. and Shelnutt, J.A. (2008) Synthesis of Platinum Nanowheels Using a Bicellar Template. Journal of American Chemical Society, 130, 12602-12603. http://dx.doi.org/10.1021/ja8047464

[78] Chen, S. and Carroll, D.L. (2004) Silver Nanoplates: Size Control in Two Dimensions and Formation Mechanisms. Journal of Physical Chemistry B, 108, 5500-5506. http://dx.doi.org/10.1021/jp031077n

[79] Chen, S., Fan, Z. and Carroll, D.L. (2002) Silver Nanodisks: Synthesis, Characterization, and Self Assembly. Journal of Physical Chemistry B, 106, 10777-10781. http://dx.doi.org/10.1021/jp026376b

[80] Chen, S. and Carroll, D.L. (2002) Synthesis and Characterization of Truncated Triangular Silver Nanoplates. Nano Letters, 2, 1003-1007. http://dx.doi.org/10.1021/nl025674h

[81] Garcia, R.M., Song, Y., Dorin, R.M., Wang, H., Moreno, A.M., Jiang, Y.B., Tian, Y., Qiu, Y., Medforth, C.J., Coker, E.N., Swol, F.V., Miller, J.E. and Shelnutt, J.A. (2011) Templated Growth of Platinum Nanowheels Using the Inhomogeneous Reaction Environment of Bicelles. Physical Chemistry Chemical Physics, 13, 4846-4852. http://dx.doi.org/10.1039/C0CP01930E

[82] Huang, X., Li, Y., Chen, Y., Zhou, H., Duan, X. and Huang, Y. (2013) Plasmonic and Catalytic AuPd Nanowheels for the Efficient Conversion of Light into Chemical Energy. Angewandte Chemie, 125, 6179-06183. http://dx.doi.org/10.1002/ange.201301096

[83] Salzemann, C., Urban, J., Lisiecki, I. and Pileni, M.P. (2005) Characterization and Growth Process of Copper Nanodisks. Advanced Functional Materials, 15, 1277-1284. http://dx.doi.org/10.1002/adfm.200400594

[84] Maillard, M., Giorgio, S. and Pileni, M.P. (2002) Silver Nanodisks. Advanced Materials, 14, 1084-1086. http://dx.doi.org/10.1002/1521-4095(20020805)14:15<1084::AID-ADMA1084>3.0.CO;2-L

[85] Maillard, M., Giorgio, S. and Pileni, M.P. (2003) Tuning the Size of Silver Nanodisks with Similar Aspect Ratios: Synthesis and Optical Properties. Journal of Physical Chemistry B, 107, 2466-2470. http://dx.doi.org/10.1021/jp022357q 
[86] Song, Y., Yang, Y., Medforth, C.J., Pereira, E., Singh, A.K., Xu, H., Jiang, Y., Brinker, C.J., Swol, F.V. and Shelnutt, J.A. (2004) Controlled Synthesis of 2D and 3D Dendritic Platinum Nanostructures. Journal of American Chemical Society, 126, 635-645. http://dx.doi.org/10.1021/ja037474t

[87] Puntes, V.F., Krishnan, K.M. and Alivisatos, A.P. (2001) Colloidal Nanocrystal Shape and Size Control: The Case of Cobalt. Science, 291, 2115-2117. http://dx.doi.org/10.1126/science.1057553

[88] Puntes, V.F., Zanchet, D., Erdonmez, C.K. and Alivisatos, A.P. (2002) Synthesis of HCP-Co Nanodisks. Journal of American Chemical Society, 124, 12874-12880. http://dx.doi.org/10.1021/ja027262g

[89] Jang, K., Kim, H.J. and Son, S.U. (2010) Low Temperature Synthesis of Ultrathin Rhodium Nanoplates via Molecular Orbital Symmetry Interaction between Rhodium Precursors. Chemistry of Materials, 22, 1273-1275. http://dx.doi.org/10.1021/cm902948v

[90] Deng, Z., Mansuipur, M. and Muscat, A.J. (2009) New Method to Single Crystal Micrometer Sized Ultra Thin Silver Nanosheets: Synthesis and Characterization. Journal of Physical Chemistry C, 113, 867-873. http://dx.doi.org/10.1021/jp809684y

[91] Guo, H., Chen, Y., Ping, H., Wang, L. and Peng, D.L. (2012) One Pot Synthesis of Hexagonal and Triangular Nickel Copper Alloy Nanoplates and Their Magnetic and Catalytic Properties. Journal of Materials Chemistry, 22, 8336-8344. http://dx.doi.org/10.1039/c2jm16095a

[92] Zhang, J.H., Liu, H.Y., Zhan, P., Wang, Z.L. and Ming, N.B. (2007) Controlling the Growth and Assembly of Silver Nanoprisms. Advanced Functional Materials, 17, 1558-1566. http://dx.doi.org/10.1002/adfm.200600727

[93] Metraux, G.S. and Mirkin, C.A. (2005) Rapid Thermal Synthesis of Silver Nanoprisms with Chemically Tailorable Thickness. Advanced Materials, 17, 412-415. http://dx.doi.org/10.1002/adma.200401086

[94] Song, J., Chu, Y., Liu, Y., Li, L. and Sun, W. (2008) Room Temperature Controllable Fabrication of Silver Nanoplates Reduced by Aniline. Chemical Communications, No. 10, 1223-1225. http://dx.doi.org/10.1039/b715884j

[95] Ah, C.S., Yun, Y.J., Park, H.J., Kim, W.J., Ha, D.H. and Yun, W.S. (2005) Size Controlled Synthesis of Machinable Single Crystalline Gold Nanoplates. Chemistry of Materials, 17, 5558-5561. http://dx.doi.org/10.1021/cm051225h

[96] Zhang, Q., Li, N., Goebl, J., Lu, Z. and Yin, Y. (2011) A Systematic Study of the Synthesis of Silver Nanoplates: Is Citrate a "Magic" Reagent? Journal of American Chemical Society, 133, 18931-18939. http://dx.doi.org/10.1021/ja2080345

[97] Xiong, Y., Washio, I., Chen, J., Cai, H., Li, Z.Y. and Xia, Y. (2006) Poly(vinyl pyrrolidone): A Dual Functional Reductant and Stabilizer for the Facile Synthesis of Noble Metal Nanoplates in Aqueous Solutions. Langmuir, 22, 8563-8570. http://dx.doi.org/10.1021/la061323x

[98] Pastoriza-Santos, I. and Liz-Marzan, L.M. (2002) Synthesis of Silver Nanoprisms in DMF. Nano Letters, 2, $903-905$. http://dx.doi.org/10.1021/nl025638i

[99] Pastoriza-Santos, I., Sánchez-Iglesias, A., Rodríguez-González, B. and Liz-Marzán, L.M. (2009) Aerobic Synthesis of Cu Nanoplates with Intense Plasmon Resonances. Small, 5, 440-443. http://dx.doi.org/10.1002/smll.200801088

[100] Porel, S., Singh, S. and Radhakrishnan, T.P. (2005) Polygonal Gold Nanoplates in a Polymer Matrix. Chemical Communication, No. 18, 2387-2389. http://dx.doi.org/10.1039/b500536a

[101] Kim, J.U., Cha, S.H., Shin, K., Jho, J.Y. and Lee, J.C. (2004) Preparation of Gold Nanowires and Nanosheets in Bulk Block Copolymer Phases under Mild Conditions. Advanced Materials, 16, 459-464. http://dx.doi.org/10.1002/adma.200305613

[102] Bagwe, R.P. and Khilar, K.C. (2000) Effects of Intermicellar Exchange Rate on the Formation of Silver Nanoparticles in Reverse Microemulsions of AOT. Langmuir, 16, 905-910. http://dx.doi.org/10.1021/la980248q

[103] Zhang, Z.Q., Patel, R.C., Kothari, R., Johnson, C.P., Friberg, S.E. and Aikens, P.A. (2000) Stable Silver Clusters and Nanoparticles Prepared in Polyacrylate and Inverse Micellar Solutions. Journal of Physical Chemistry B, 104, 11761182. http://dx.doi.org/10.1021/jp991569t

[104] Zhang, W.Z., Qiao, X.L., Chen, J.G. and Chen, Q.Y. (2008) Self Assembly and Controlled Synthesis of Silver Nanoparticles in SDS Quaternary Microemulsion. Material Letters, 62, 1689-1692. http://dx.doi.org/10.1016/j.matlet.2007.09.060

[105] Ito, T. and Okazaki, S. (2000) Pushing the Limits of Lithography. Nature, 406, 1027-1031. http://dx.doi.org/10.1038/35023233

[106] Kim, S.E., Han, Y.H., Lee, B.C. and Lee, J.C. (2010) One Pot Fabrication of Various Silver Nanostructures on Substrates Using Electron Beam Irradiation. Nanotechnology, 21, Article ID: 075302. http://dx.doi.org/10.1088/0957-4484/21/7/075302

[107] Reyntjens, S. and Puers, R. (2000) Focused Ion Beam Induced Deposition: Fabrication of Three Dimensional Microstructures and Young's Modulus of the Deposited Material. Journal of Micromechanics and Microengineering, 10, 
181-188. http://dx.doi.org/10.1088/0960-1317/10/2/314

[108] Duan, H., Wang, D., Kurth, D.G. and Möhwald, H. (2004) Directing Self Assembly of Nanoparticles at Water/Oil Interfaces. Angewandte Chemie International Edition, 43, 5639-5642. http://dx.doi.org/10.1002/anie.200460920

[109] Korgel, B.A., Fullam, S., Connolly, S. and Fitzmaurice, D. (1998) Assembly and Self Organization of Silver Nanocrystal Superlattices: Ordered “Soft Spheres”. Journal of Physical Chemistry B, 102, 8379-8388. http://dx.doi.org/10.1021/jp9815980

[110] Martin, J.E., Wilcoxon, J.P., Odinek, J. and Provencio, P. (2000) Control of the Interparticle Spacing in Gold Nanoparticle Superlattices. Journal Physical Chemistry B, 104, 9475-9486. http://dx.doi.org/10.1021/jp001292t

[111] Cheng, W., Campolongo, M.J., Cha, J.J., Tan, S.J., Umbach, C.C., Muller, D.A. and Luo, D. (2009) Free Standing Nanoparticle Superlattice Sheets Controlled by DNA. Nature Materials, 8, 519-525. http://dx.doi.org/10.1038/nmat2440

[112] Chen, Y. and Cheng, W. (2012) DNA Based Plasmonic Nanoarchitectures: From Structural Design to Emerging Applications. Wiley Interdisciplinary Reviews: Nanomedicine and Nanobiotechnology, 4, 587-604. http://dx.doi.org/10.1002/wnan.1184

[113] Ofir, Y., Samanta, B. and Rotello, V.M. (2008) Polymer and Biopolymer Mediated Self Assembly of Gold Nanoparticles. Chemical Society Reviews, 37, 1814-1825. http://dx.doi.org/10.1039/b712689c

[114] Wu, Z., Dong, C., Li, Y., Hao, H., Zhang, H., Lu, Z. and Yang, B. (2013) Self Assembly of Au15 into Single Cluster Thick Sheets at the Interface of Two Miscible High-Boiling Solvents. Angewandte Chemie, 125, 10136-10139. http://dx.doi.org/10.1002/ange.201304122

[115] Bigioni, T.P., Lin, X.M., Nguyen, T.T., Corwin, E.I., Witten, T.A. and Jaeger, H.M. (2006) Kinetically Driven Self Assembly of Highly Ordered Nanoparticle Monolayers. Nature Materials, 5, 265-270. http://dx.doi.org/10.1038/nmat1611

[116] Nykypanchuk, D., Maye, M.M., Van der Lelie, D. and Gang, O. (2008) DNA-Guided Crystallization of Colloidal Nanoparticles. Nature, 451, 549-552. http://dx.doi.org/10.1038/nature06560

[117] Deng, Z., Tian, Y., Lee, S.H., Ribbe, A.E. and Mao, C. (2005) DNA Encoded Self Assembly of Gold Nanoparticles into One Dimensional Arrays. Angewandte Chemie International Edition, 44, 3582-3585. http://dx.doi.org/10.1002/anie.200463096

[118] Aldaye, F.A. and Sleiman, H.F. (2007) Dynamic DNA Templates for Discrete Gold Nanoparticle Assemblies: Control of Geometry, Modularity, Write/Erase and Structural Switching. Journal of American Chemical Society, 129, 41304131. http://dx.doi.org/10.1021/ja070017i

[119] Maye, M.M., Nykypanchuk, D., Cuisinier, M., Van der Lelie, D. and Gang, O. (2009) Stepwise Surface Encoding for High-Throughput Assembly of Nanoclusters. Nature Materials, 8, 388-391. http://dx.doi.org/10.1038/nmat2421

[120] Elbaz, J., Cecconello, A., Fan, Z., Govorov, A.O. and Willner, I. (2013) Powering the Programmed Nanostructure and Function of Gold Nanoparticles with Catenated DNA Machines. Nature Communications, 4, 2000. http://dx.doi.org/10.1038/ncomms3000

[121] Jones, M.R., Osberg, K.D., Macfarlane, R.J., Langille, M.R. and Mirkin, C.A. (2011) Templated Techniques for the Synthesis and Assembly of Plasmonic Nanostructures. Chemical Reviews, 111, 3736-3827. http://dx.doi.org/10.1021/cr1004452

[122] Yin, A.X., Liu, W.C., Ke, J., Zhu, W., Gu, J., Zhang, Y.W. and Yan, C.H. (2012) Ru Nanocrystals with Shape Dependent Surface Enhanced Raman Spectra and Catalytic Properties: Controlled Synthesis and DFT Calculations. Journal of American Chemical Society, 134, 20479-20489. http://dx.doi.org/10.1021/ja3090934

[123] Liu, B. and Zeng, H.C. (2003) Hydrothermal Synthesis of ZnO Nanorods in the Diameter Regime of $50 \mathrm{~nm}$. Journal of American Chemical Society, 125, 4430-4431. http://dx.doi.org/10.1021/ja0299452

[124] Yang, Y., Zhong, X.L., Zhang, Q., Blackstad, L.G., Fu, Z.W., Li, Z.Y. and Qin, D. (2014) The Role of Etching in the Formation of Ag Nanoplates with Straight, Curved and Wavy Edges and Comparison of Their SERS Properties. Small, 10, 1430-1437. http://dx.doi.org/10.1002/smll.201302877

[125] Kowshik, M., Deshmukh, N., Vogel, W., Urban, J., Kulkarni, S.K. and Paknikar, M.K. (2002) Microbial Synthesis of Semiconductor CdS Nanoparticles, Their Characterization, and Their Use in the Fabrication of an Ideal Diode. Biotechnology and Bioengineering, 28, 583-588. http://dx.doi.org/10.1002/bit.10233

[126] Bansal, V., Poddar, P., Ahmad, A. and Sastry, M. (2006) Room Temperature Biosynthesis of Ferroelectric Barium Titanate Nanoparticles. Journal of American Chemical Society, 128, 11958-11963. http://dx.doi.org/10.1021/ja063011m

[127] Bansal, V., Rautaray, D., Ahmad, A. and Sastry, M. (2004) Biosynthesis of Zirconia Nanoparticles Using the Fungus Fusarium Oxysporum. Journal of Materials Chemistry, 14, 3303-3305. http://dx.doi.org/10.1039/b407904c

[128] Ankamwar, B., Chaudhary, M. and Sastry, M. (2005) Gold Nanotriangles Biologically Synthesized Using Tamarind 
Leaf Extract and Potential Application in Vapor Sensing. Synthesis and Reactivity in Inorganic Metal-Organic and Nano Metal Chemistry, 35, 19-26. http://dx.doi.org/10.1081/SIM-200047527

[129] Armendariz, V., Herrera, I., Peralta-Videa, J.R., Jose-Yacaman, M., Troiani, H., Santiago, P. and Gardea-Torresdey, J.R. (2004) Size Controlled Gold Nanoparticle Formation by Avena sativa Biomass: Use of Plants in Nanobiotechnology. Journal of Nanoparticle Research, 6, 377-382. http://dx.doi.org/10.1007/s11051-004-0741-4

[130] Gericke, M. and Pinches, A. (2006) Biological Synthesis of Metal Nanoparticles. Hydrometallurgy, 83, $132-140$. http://dx.doi.org/10.1016/j.hydromet.2006.03.019

[131] Sastry, M., Ahmad, A., Islam Khan, M. and Kumar, R. (2003) Biosynthesis of Metal Nanoparticles Using Fungi and Actinomycete. Current Science India, 85, 162-170.

[132] Tong, H., Ouyang, S.X., Bi, Y.P., Umezawa, N., Oshikiri, M. and Ye, J.H. (2012) Nano Photocatalytic Materials: Possibilities and Challenges. Advanced Materials, 24, 229-251. http://dx.doi.org/10.1002/adma.201102752

[133] Pelizzetti, E. and Minero, C. (1994) Metal Oxides as Photocatalysts for Environmental Detoxification. Comments on Inorganic Chemistry, 15, 297-337. http://dx.doi.org/10.1080/02603599408035846

[134] Hisatomi, T., Kubota, J. and Domen, K. (2014) Recent Advances in Semiconductors for Photocatalytic and Photoelectrochemical Water Splitting. Chemical Society Reviews, 43, 7520-7535. http://dx.doi.org/10.1039/C3CS60378D

[135] Hoffmann, M.R., Martin, S.T., Choi, W. and Bahnemann, D.W. (1995) Environmental Applications of Semiconductor Photocatalysis. Chemical Reviews, 95, 69-96. http://dx.doi.org/10.1021/cr00033a004

[136] Ndez-Ramírez, A.H. and Medina-Ramírez, I. (2015) Photocatalytic Semiconductors. Springer, New York.

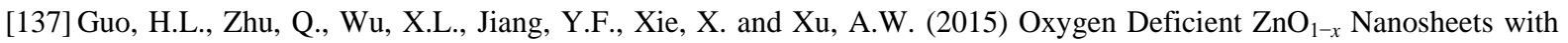
High Visible Light Photocatalytic Activity. Nanoscale, 7, 7216-7223. http://dx.doi.org/10.1039/C5NR00271K Ansari, S.A., Khan, M.M., Ansari, M.O. and Cho, M.H. (2015) Silver Nanoparticles and Defect Induced Visible Light Photocatalytic and Photoelectrochemical Performance of Ag@ m- $\mathrm{TiO}_{2}$ Nanocomposite. Solar Energy Materials and Solar Cells, 141, 162-170. http://dx.doi.org/10.1016/j.solmat.2015.05.029

Wang, W.S., Du, H., Wang, R.X., Wen, T. and Xu, A.W. (2013) Heterostructured $\mathrm{Ag}_{3} \mathrm{PO}_{4} / \mathrm{AgBr} / \mathrm{Ag}$ Plasmonic Photocatalyst with Enhanced Photocatalytic Activity and Stability under Visible Light. Nanoscale, 5, 3315-3321. http://dx.doi.org/10.1039/c3nr00191a

[138] Fujishima, A. and Honda, K. (1972) Electrochemical Photolysis of Water at a Semiconductor Electrode. Nature, 238, 37-39. http://dx.doi.org/10.1038/238037a0

[139] Lim, J.H., Kang, C.K., Kim, K.K., Park, I.K., Hwang, D.K. and Park, S.J. (2006) UV Electroluminescence Emission from ZnO Light Emitting Diodes Grown by High Temperature Radiofrequency Sputtering. Advanced Materials, 18, 2720-2724. http://dx.doi.org/10.1002/adma.200502633

[140] Asai, R., Nemoto, H., Jia, Q., Saito, K., Iwase, A. and Kudo, A. (2014) A Visible Light Responsive Rhodium and Antimony Codoped $\mathrm{SrTiO}_{3}$ Powdered Photocatalyst Loaded with an $\mathrm{IrO}_{2}$ Cocatalyst for Solar Water Splitting. Chemical Communications, 50, 2543-2546. http://dx.doi.org/10.1039/c3cc49279f

Hisatomi, T., Kubota, J. and Domen, K. (2014) Recent Advances in Semiconductors for Photocatalytic and Photoelectrochemical Water Splitting. Chemical Society Reviews, 43, 7520-7535. http://dx.doi.org/10.1039/C3CS60378D

[141] Pan, C., Takata, T., Nakabayashi, M., Matsumoto, T., Shibata, N., Ikuhara, Y. and Domen, K. (2015) A Complex Perovskite Type Oxynitride: The First Photocatalyst for Water Splitting Operable at up to $600 \mathrm{~nm}$. Angewandte Chemie International Edition, 54, 2955-2959. http://dx.doi.org/10.1002/anie.201410961

[142] Du, H., Xie, X., Zhu, Q., lin, L., Jiang, Y.F., Yang, Z.K., Zhou, X. and Xu, A.W. (2015) Metallic $\mathrm{MoO}_{2} \mathrm{Cocatalyst}$ Significantly Enhances Visible Light Photocatalytic Hydrogen Production Over $\mathrm{MoO}_{2} / \mathrm{Zn}_{0.5} \mathrm{Cd}_{0.5} \mathrm{~S}$ Heterojunction. Nanoscale, 7, 5752-5759. http://dx.doi.org/10.1039/C4NR06949H

Chang, K., Mei, Z., Wang, T., Kang, Q., Ouyang, S. and Ye, J. (2014) $\mathrm{MoS}_{2} /$ Graphene Cocatalyst for Efficient Photocatalytic $\mathrm{H}_{2}$ Evolution under Visible Light Irradiation. ACS Nano, 8, 7078-7087.

http://dx.doi.org/10.1021/nn5019945

Wu, B. and Zheng, N. (2013) Surface and Interface Control of Noble Metal Nanocrystals for Catalytic and Electrocatalytic Applications. Nanotoday, 8, 168-197. http://dx.doi.org/10.1016/j.nantod.2013.02.006

[143] Yu, Q., Guan, P., Qin, D., Golden, G. and Wallace, P.M. (2008) Inverted Size Dependence of Surface Enhanced Raman Scattering on Gold Nanohole and Nanodisk Arrays. Nano Letters, 8, 1923-1928. http://dx.doi.org/10.1021/nl0806163

[144] Zhang, X.Y., Hu, A., Zhang, T., Lei, W., Xue, X.J., Zhou, Y. and Duley, W.W. (2011) Self Assembly of Large Scale and Ultrathin Silver Nanoplate Films with Tunable Plasmon Resonance Properties. ACS Nano, 5, 9082-9092. http://dx.doi.org/10.1021/nn203336m

[145] Lu, G., Li, H., Liusman, C., Yin, Z., Wu, S. and Zhang, H. (2011) Surface Enhanced Raman Scattering of Ag or Au Nanoparticle Decorated Reduced Graphene Oxide for Detection of Aromatic Molecules. Chemical Science, 2, 1817 1821. http://dx.doi.org/10.1039/c1sc00254f 
[146] Lu, G., Li, H. and Zhang, H. (2012) Gold Nanoparticle Embedded Polydimethylsiloxane Elastomers for Highly Sensitive Raman Detection. Small, 8, 1336-1340. http://dx.doi.org/10.1002/smll.201102258

[147] Sun, Y. and Wiederrecht, G.P. (2007) Surfactantless Synthesis of Silver Nanoplates and Their Application in SERS. Small, 3, 1964-1975. http://dx.doi.org/10.1002/smll.200700484

[148] Banholzer, M.J., Millstone, J.E., Qin, L. and Mirkin, C.A. (2008) Rationally Designed Nanostructures for Surface Enhanced Raman Spectroscopy. Chemical Society Reviews, 37, 885-897. http://dx.doi.org/10.1039/b710915f

[149] Kneipp, J., Kneipp, H. and Kneipp, K. (2008) SERS a Single Molecule and Nanoscale Tool for Bioanalytics. Chemical Society Reviews, 37, 1052-1060. http://dx.doi.org/10.1039/b708459p

[150] Qian, X.M. and Nie, S.M. (2008) Single Molecule and Single Nanoparticle SERS: From Fundamental Mechanisms to Biomedical Applications. Chemical Society Reviews, 37, 912-920. http://dx.doi.org/10.1039/b708839f

[151] Zoric, I., Zäch, M., Kasemo, B. and Langhammer, C. (2011) Gold, Platinum, and Aluminum Nanodisk Plasmons: Material Independence, Subradiance, and Damping Mechanisms. ACS Nano, 5, 2535-2546. http://dx.doi.org/10.1021/nn102166t

[152] Moskovits, M. (2005) Surface Enhanced Raman Spectroscopy: A Brief Retrospective. Journal of Raman Spectroscopy, 36, 485-496. http://dx.doi.org/10.1002/jrs.1362

[153] Le Ru, E.C. and Etchegoin, P.G. (2006) Rigorous Justification of the $|E| 4$ Enhancement Factor in Surface Enhanced Raman Spectroscopy. Chemical Physics Letters, 423, 63-66. http://dx.doi.org/10.1016/j.cplett.2006.03.042

[154] Haynes, C.L., McFarland, A.D. and Duyne, R.P.V. (2005) Surface Enhanced Raman Spectroscopy. Analytical Chemistry, 77, 338A-346A. http://dx.doi.org/10.1021/ac053456d

[155] Viarbitskaya, S., Teulle, A., Marty, R., Sharma, J., Girard, C., Arbouet, A. and Dujardin, E. (2013) Tailoring and Imaging the Plasmonic Local Density of States in Crystalline Nanoprisms. Nature Materials, 12, 426-432. http://dx.doi.org/10.1038/nmat3581

[156] Bae, Y., Kim, N.H., Kim, M., Lee, K.Y. and Han, S.W. (2008) Anisotropic Assembly of Ag Nanoprisms. Journal of American Chemical Society, 130, 5432-5433. http://dx.doi.org/10.1021/ja800898v

[157] Xiong, Y., McLellan, J.M., Chen, J., Yin, Y., Li, Z.Y. and Xia, Y. (2005) Kinetically Controlled Synthesis of Triangular and Hexagonal Nanoplates of Palladium and their SPR/SERS Properties. Journal of American Chemical Society, 127, 17118-17127. http://dx.doi.org/10.1021/ja056498s

[158] Huang, X., Tang, S., Liu, B., Ren, B. and Zheng, N. (2011) Enhancing the Photothermal Stability of Plasmonic Metal Nanoplates by a Core Shell Architecture. Advanced Materials, 23, 3420-3425. http://dx.doi.org/10.1002/adma.201100905

[159] Pillai, Z.S. and Kamat, P.V. (2004) What Factors Control the Size and Shape of Silver Nanoparticles in the Citrate ion Reduction Method? Journal of Physical Chemistry B, 108, 945-951. http://dx.doi.org/10.1021/jp037018r

[160] Wustholz, K.L., Henry, A.I., Bingham, J.M., Kleinman, S.L., Natan, M.J., Freeman, R.G. and Duyne, R.P.V. (2009) Exploring Single Molecule SERS and Single Nanoparticle Plasmon Microscopy. Proceedings SPIE, 7394, Article ID: 739403. http://dx.doi.org/10.1117/12.826168

[161] Camargo, P.H.C., Rycenga, M., Au, L. and Xia, Y. (2009) Isolating and Probing the Hot Spot Formed between Two Silver Nanocubes. Angewandte Chemie International Edition, 48, 2180-2184. http://dx.doi.org/10.1002/anie.200806139

[162] Camargo, P.H.C., Cobley, C.M., Rycenga, M. and Xia, Y. (2009) Measuring the Surface Enhanced Raman Scattering Enhancement Factors of Hot Spots Formed between an Individual Ag Nanowire and a Single Ag Nanocube. Nanotechnology, 20, Article ID: 434020. http://dx.doi.org/10.1088/0957-4484/20/43/434020

[163] Dieringer, J.A., Lettan, R.B., Scheidt, K.A. and Van Duyne, R.P. (2007) A Frequency Domain Existence Proof of Single Molecule Surface Enhanced Raman Spectroscopy. Journal of American Chemical Society, 129, 16249-16256. http://dx.doi.org/10.1021/ja077243c

[164] Li, W., Camargo, P.H.C., Lu, X. and Xia, Y. (2008) Dimers of Silver Nanospheres: Facile Synthesis and Their Use as Hot Spots for Surface Enhanced Raman Scattering. Nano Letters, 9, 485-490. http://dx.doi.org/10.1021/nl803621x

[165] LeRu, E., Meyer, M. and Etchegoin, P. (2006) Proof of Single Molecule Sensitivity in Surface Enhanced Raman Scattering (SERS) by Means of a Two Analyte Technique. Journal of Physical Chemistry B, 110, 1944-1948. http://dx.doi.org/10.1021/jp054732v

[166] Fang, Y., Seong, N.H. and Dlott, D.D. (2008) Measurement of the Distribution of Site Enhancements in Surface Enhanced Raman Scattering. Science, 321, 388-392. http://dx.doi.org/10.1126/science.1159499

[167] Maier, S. (2007) Plasmonics: Fundamentals and Applications. Springer, New York.

[168] Kelly, K., Coronado, E., Zhao, L. and Schatz, G. (2003) The Optical Properties of Metal Nanoparticles: The Influence of Size, Shape, and Dielectric Environment. Journal of Physical Chemistry B, 107, 668-677. 
http://dx.doi.org/10.1021/jp026731y

[169] Grady, N., Halas, N. and Nordlander, P. (2004) Influence of Dielectric Function Properties on the Optical Response of Plasmon Resonant Metallic Nanoparticles. Chemical Physics Letters, 399, 167-171. http://dx.doi.org/10.1016/j.cplett.2004.09.154

[170] Mock, J.J., Smith, D.R. and Schultz, S. (2003) Local Refractive Index Dependence of Plasmon Resonance Spectra from Individual Nanoparticles. Nano Letters, 3, 485-491. http://dx.doi.org/10.1021/nl0340475

[171] Underwood, S. and Mulvaney, P. (1994) Effect of the Solution Refractive Index on the Color of Gold Colloids. Langmuir, 10, 3427-3430. http://dx.doi.org/10.1021/la00022a011

[172] Ni, W., Chen, H., Su, J., Sun, Z., Wang, J. and Wu, H. (2010) Effects of Dyes, Gold Nanocrystals, pH, and Metal Ions on Plasmonic and Molecular Resonance Coupling. Journal of American Chemical Society, 132, 4806-4814. http://dx.doi.org/10.1021/ja910239b

[173] Zeng, J., Roberts, S. and Xia, Y. (2010) Nanocrystal Based Time Temperature Indicators. Chemistry European Journal, 16, 12559-12563. http://dx.doi.org/10.1002/chem.201002665

[174] Huang, X., Tang, S., Mu, X., Dai, Y., Chen, G., Zhou, Z., Ruan, F., Yang, Z. and Zheng, N. (2011) Free Standing Palladium Nanosheets with Plasmonic and Catalytic Properties. Nature Nanotechnology, 6, 28-32. http://dx.doi.org/10.1038/nnano.2010.235

[175] Pelaz, B., Grazu, V., Ibarra, A., Magen, C., del Pino, P. and de la Fuente, J.M. (2012) Tailoring the Synthesis and Heating Ability of Gold Nanoprisms for Bioapplications. Langmuir, 28, 8965-8970. http://dx.doi.org/10.1021/la204712u

[176] Huang, X., Tang, S., Liu, B., Ren, B. and Zheng, N. (2011) Enhancing the Photothermal Stability of Plasmonic Metal Nanoplates by a Core Shell Architecture. Advanced Materials, 23, 3420-3425. http://dx.doi.org/10.1002/adma.201100905

[177] Xue, C. and Mirkin, C.A. (2007) pH Switchable Silver Nanoprism Growth Pathways. Angewandte Chemie, 119, 20822084. http://dx.doi.org/10.1002/ange.200604637

[178] Tang, S., Chen, M. and Zheng, N. (2014) Sub $10 \mathrm{~nm}$ Pd Nanosheets with Renal Clearance for Efficient near Infrared Photothermal Cancer Therapy. Small, 10, 3139-3144. http://dx.doi.org/10.1002/smll.201303631

[179] Huang, X., Tang, S., Yang, J., Tan, Y. and Zheng, N. (2011) Etching Growth under Surface Confinement: An Effective Strategy to Prepare Mesocrystalline Pd Nanocorolla. Journal of American Chemical Society, 133, 15946-15949. http://dx.doi.org/10.1021/ja207788h

[180] Zhao, Z., Shi, S., Huang, Y., Tang, S. and Chen, X. (2014) Simultaneous Photodynamic and Photothermal Therapy Using Photosensitizer Functionalized Pd Nanosheets by Single Continuous Wave Laser. ACS Applied Materials Interfaces, 6, 8878-8885. http://dx.doi.org/10.1021/am501608c

[181] Fang, W., Tang, S., Liu, P., Fang, X., Gong, J. and Zheng, N. (2012) Pd Nanosheet Covered Hollow Mesoporous Silica Nanoparticles as a Platform for the Chemo Photothermal Treatment of Cancer Cells. Small, 8, 3816-3822. http://dx.doi.org/10.1002/smll.201200962

[182] Tam, F., Goodrich, G.P., Johnson, B.R. and Halas, N.J. (2007) Plasmonic Enhancement of Molecular Fluorescence. Nano Letters, 7, 496-501. http://dx.doi.org/10.1021/nl062901x

[183] Shang, L., Chen, H. and Dong, S. (2007) Electrochemical Preparation of Silver Nanostructure on the Planar Surface for Application in Metal Enhanced Fluorescence. Journal of Physical Chemistry C, 111, 10780-10784. http://dx.doi.org/10.1021/jp068713c

[184] Liaw, J.W., Chen, J.H., Chen, C.S. and Kuo, M.K. (2009) Purcell Effect of Nanoshell Dimer on Single Molecule's Fluorescence. Optics Express, 17, 13532-13540. http://dx.doi.org/10.1364/OE.17.013532

[185] Thomas, M., Greffet, J.J., Carminati, R. and Arias-Gonzalez, J.R. (2004) Single Molecule Spontaneous Emission Close to Absorbing Nanostructures. Applied Physics Letters, 85, 3863-3865. http://dx.doi.org/10.1063/1.1812592

[186] Carminati, R., Greffet, J.J., Henkel, C. and Vigoureux, J. (2006) Radiative and Non Radiative Decay of a Single Molecule Close to a Metallic Nanoparticle. Optics Communications, 261, 368-375. http://dx.doi.org/10.1016/j.optcom.2005.12.009

[187] Martin-Moreno, L. (2006) Detecting Unseen Light. Nature Physics, 5, 457-458. http://dx.doi.org/10.1038/nphys1314

[188] Ozbay, E. (2006) Plasmonics: Merging Photonics and Electronics at Nanoscale Dimensions. Science, 311, $189-193$. http://dx.doi.org/10.1126/science.1114849

[189] Lewotsky, K. (2007) The Promise of Plasmonics. SPIE Professional. http://dx.doi.org/10.1117/2.4200707.07

[190] Yan, R., Gargas, D. and Yang, P. (2009) Nanowire Photonics. Nature Photonics, 3, 569-576. http://dx.doi.org/10.1038/nphoton.2009.184 
[191] Shegai, T., Huang, Y., Xu, H. and Kall, M. (2010) Coloring Fluorescence Emission with Silver Nanowires. Applied Physics Letters, 96, Article ID: 103114. http://dx.doi.org/10.1063/1.3355545

[192] Akimov, A.V., Mukherjee, A., Yu, C.L., Chang, D.E., Zibrov, A.S., Hemmer, P.R., Park, H. and Lukin, M.D. (2007) Generation of Single Optical Plasmons in Metallic Nanowires Coupled to Quantum Dots. Nature, 450, 402-406. http://dx.doi.org/10.1038/nature06230

[193] Ma, Z., Zhang, X., Guo, X., Yang, Q., Ma, Y. and Tong, L. (2010) Surface Plasmon Excitation in Silver Nanowires Directly Deposited on a Laser Diode Chip. Applied Physics Letters, 96, Article ID: 051119. http://dx.doi.org/10.1063/1.3294626

[194] Prof. Choi Unveils Method to Improve Emission Efficiency of OLED. KAIST, 9 July 2009.

[195] Wiley, B., Sun, Y. and Xia, Y. (2007) Synthesis of Silver Nanostructures with Controlled Shapes and Properties. Accounts of Chemical Research, 40, 1067-1076. http://dx.doi.org/10.1021/ar7000974

[196] Xia, Y., Xiong, Y., Lim, B. and Skrabalak, S.E. (2009) Shape Controlled Synthesis of Metal Nanocrystals: Simple Chemistry Meets Complex Physics? Angewandte Chemie International Edition, 48, 60-103. http://dx.doi.org/10.1002/anie.200802248

[197] Cobley, C.M., Skrabalak, S.E., Campbell, D.J. and Xia, Y. (2009) Shape Controlled Synthesis of Silver Nanoparticles for Plasmonic and Sensing Applications. Plasmonics, 4, 171-179. http://dx.doi.org/10.1007/s11468-009-9088-0

[198] Xia, Y. and Halas, N. (2005) Shaped Controlled Synthesis and Surface Plasmonic Properties of Metallic Nanostructures. MRS Bulletin, 30, 338-348. http://dx.doi.org/10.1557/mrs2005.96

[199] Zhang, X., Hicks, E.M., Zhao, J., Schatz, G.C. and Van Duyne, R.P. (2005) Electrochemical Tuning of Silver Nanoparticles Fabricated by Nanosphere Lithography. Nano Letters, 5, 1503-1507. http://dx.doi.org/10.1021/nl050873x

[200] Atwater, H.A. and Polman, A. (2010) Plasmonics for Improved Photovoltaic Devices. Nature Materials, 9, $205-213$. http://dx.doi.org/10.1038/nmat2629

[201] Rand, B.P., Peumans, P. and Forrest, S.R. (2004) Long Range Absorption Enhancement in Organic Tandem Thin Film Solar Cells Containing Silver Nanoclusters. Journal of Applied Physics, 96, 7519-7526. http://dx.doi.org/10.1063/1.1812589

[202] Shen, H., Bienstman, P. and Maes, B. (2009) Plasmonic Absorption Enhancement in Organic Solar Cells with Thin Active Layers. Journal of Applied Physics, 106, Article ID: 073109. http://dx.doi.org/10.1063/1.3243163

[203] MacDonald, K.F., Samson, Z.L., Stockman, M.I. and Zheludev, N.I. (2009) Ultrafast Active Plasmonics. Nature Photonics, 3, 55-58. http://dx.doi.org/10.1038/nphoton.2008.249

[204] Fang, N., Lee, H., Sun, C. and Zhang, X. (2005) Sub Diffraction Limited Optical Imaging with a Silver Superlens. Science, 308, 534-537. http://dx.doi.org/10.1126/science.1108759

[205] Kawata, S., Ono, A. and Verma, P. (2008) Sub Wavelength Colour Imaging with a Metallic Nanolens. Nature Photonics, 2, 438-442. http://dx.doi.org/10.1038/nphoton.2008.103

[206] Yuan, H., Chettiar, U.K., Cai, W., Kildishev, A.V., Boltasseva, A., Drachev, V.P. and Shalaev, V.M. (2007) A Negative Permeability Material at Red Light. Optics Express, 15, 1076-1083. http://dx.doi.org/10.1364/OE.15.001076

[207] Gordon, J.A. and Ziolkowski, R.W. (2007) The Design and Simulated Performance of a Coated Nano Particle Laser. Optics Express, 15, 2622-2653. http://dx.doi.org/10.1364/OE.15.002622

[208] Bergman, D.J. and Stockman, M.I. (2003) Surface Plasmon Amplification by Stimulated Emission of Radiation: Quantum Generation of Coherent Surface Plasmons in Nanosystems. Physical Review Letters, 90, Article ID: 027402. http://dx.doi.org/10.1103/PhysRevLett.90.027402

[209] Zheng, Y.B., Yang, Y.W., Jensen, L., Fang, L., Juluri, B.K., Flood, A.H., Weiss, P.S., Stoddart, J.F. and Huang, T.J. (2009) Active Molecular Plasmonics: Controlling Plasmon Resonances with Molecular Switches. Nano Letters, 9, 819825. http://dx.doi.org/10.1021/nl803539g

[210] Noginov, M.A., Zhu, G., Belgrave, A.M., Bakker, R., Shalaev, V.M., Narimanov, E.E., Stout, S., Herz, E., Suteewong, T. and Wiesner, U. (2009) Demonstration of a Spaser Based Nanolaser. Nature, 460, 1110-1112. http://dx.doi.org/10.1038/nature08318

[211] Oulton, R.F., Sorger, V.J., Zentgraf, T., Ma, R.M., Gladden, C., Dai, L., Bartal, G. and Zhang, X. (2009) Plasmon Lasers at Deep Sub Wavelength Scale. Nature, 461, 629-632. http://dx.doi.org/10.1038/nature08364

[212] MacDonald, K.F., Fedotov, V.A. and Zheludev, N.I. (2003) Optical Nonlinearity Resulting from a Light Induced Structural Transition in Gallium Nanoparticles. Applied Physics Letters, 82, 1087-1089. http://dx.doi.org/10.1063/1.1543644

[213] Leroux, Y.R., Lacroix, J.C., Chane-Ching, K.I., Fave, C., Flidj, N., Lvi, G., Aubard, J., Krenn, J.R. and Hohenau, A. (2005) Conducting Polymer Electrochemical Switching as an Easy Means for Designing Active Plasmonic Devices. Journal of American Chemical Society, 127, 16022-16023. http://dx.doi.org/10.1021/ja054915v 